\title{
Evaluation of the alcazar scoring system in differentiating benign from malignant ovarian tumors
}

\author{
Sahu Mahija, Nathasha HK*
}

Department of Obstetrics and Gynaecology, SCB Medical College \& Hospital, Cuttack-753007, Odisha, India

Received: 03 May 2015

Revised: 14 July 2015

Accepted: 22 July 2015

\author{
*Correspondence: \\ Dr. Nathasha HK, \\ E-mail: nathashahk87@gmail.com
}

Copyright: $($ ) the author(s), publisher and licensee Medip Academy. This is an open-access article distributed under the terms of the Creative Commons Attribution Non-Commercial License, which permits unrestricted non-commercial use, distribution, and reproduction in any medium, provided the original work is properly cited.

\begin{abstract}
Background: To evaluate prospectively the diagnostic performance of Alcazar scoring system to differentiate Benign from Malignant ovarian tumors using gray scale ultrasonography and color Doppler.

Methods: The prospective cohort study was conducted from January 2014 to August 2014 in the department of Obstetrics and Gynecology, SCBMCH, Cuttack. The study includes 54 patients with ovarian tumors and all were subjected to ultrasound and color Doppler. The data obtained was used to score according to ALCAZAR system and the probability of malignancy was determined. The efficacy of the scoring system was evaluated by histopathological examination of the tumor and the ascitic fluid cytology as gold standard.

Results: Of the 54 cases, Alcazar scoring system identified 22 out of 25 malignant tumors and 27 out of 29 benign tumors. The sensitivity and specificity of the scoring system for diagnosing malignancy are $88 \%$ and $93.1 \%$ respectively. The positive predictive value and negative predictive value are $91 \%$ and $90 \%$ respectively.

Conclusions: Alcazar scoring system is more specific as a diagnostic tool to rule out malignancy and can be used to differentiate benign from malignant ovarian tumors. The main disadvantage being, it is operator dependent.
\end{abstract}

Keywords: Ovarian mass, Ultrasonography with color Doppler, Alcazar scoring system, Histopathology

\section{INTRODUCTION}

Ovarian masses are the frequent reason for referral to specialist gynecologists. The differential diagnosis vary from benign to malignant tumors. To arrive at an accurate diagnosis and optimal $1^{\text {st }}$ line treatment, a noninvasive diagnostic technique became very essential. ${ }^{4,9,10}$ Hence various scoring systems have been developed to differentiate benign from malignant ovarian masses. ${ }^{7}$ Alcazar, ${ }^{1}$ Sassone, ${ }^{4}$ De Priest,${ }^{5}$ Ferrazi ${ }^{6}$ are some among the sonographic scoring systems. The present study was conducted to evaluate Alcazar scoring system. Alcazar and coworkers developed a scoring system that was based on morphology and Doppler sonography. ${ }^{1}$ The scoring system was designed to use only those parameters that are found to be independent predictors of malignancy. ${ }^{1}$ The sensitivity and specificity was found to be maximum with good accuracy.1,9

\section{Aims and objectives}

To evaluate prospectively the diagnostic performance of Alcazar scoring system to differentiate Benign from Malignant ovarian tumors using ultrasonography and color Doppler.

\section{METHODS}

A prospective cohort study was conducted from January 2014 to August 2014. The study includes all patients 
admitted to the Dept of O\&G with suspected ovarian mass. A detailed history was taken and complete clinical examination was done. All these patients were subjected to ultrasonography (Voluson P8 ultrasound machine) and color Doppler of the abdomen and pelvis. Independent parameters used were: USG parameters (Echogenicity, presence or absence of solid areas, wall thickness, septations and its thickness, papillary projections, tumor size). ${ }^{1}$ Doppler parameters (blood flow-absent or present, location of blood flow-central or peripheral velocimetryresistance index, peak systolic velocity. ${ }^{1}$ High velocity$\mathrm{PSV} \geq 10 \mathrm{cms} / \mathrm{s}$, Low resistance- $\mathrm{RI} \leq 0.45$. In tumors with both central and peripheral flow central flow was used for analysis. In those with $>1$ vessel, the lowest RI and highest PSV was used. ${ }^{1}$

The Data obtained was used to score each patient according to alcazar scoring system. The Alcazar score was evaluated for its ability to accurately diagnose malignancy. A score of $>6$ was considered cut off for malignancy. Histopathology of the tumor and the ascitic fluid cytology was used as gold standard. Age distribution, menopausal status and the pathological type of ovarian tumor was studied. Clinical features and investigations were co related with their pathological tumor type. All the data was tabulated using Microsoft excel 2007.The statistical analysis was done using Pearson chi square test in SPSS Version 20 (Table 1).

Table 1: Alcazar scoring system.

\begin{tabular}{|lllll|}
\hline Score & $\begin{array}{l}\text { Thick } \\
\text { papillary } \\
\text { projections }\end{array}$ & $\begin{array}{l}\text { Solid } \\
\text { areas }\end{array}$ & $\begin{array}{l}\text { Blood } \\
\text { flow } \\
\text { location }\end{array}$ & Velocimetry \\
\hline 0 & Absent & Absent & $\begin{array}{l}\text { Absent or } \\
\text { peripheral }\end{array}$ & Other \\
\hline & & & $\begin{array}{l}\text { High } \\
\text { velocity } \\
\text { /low } \\
\text { resistance }\end{array}$ \\
\hline 2 & Present & - & - & - \\
\hline
\end{tabular}

Score $<6-$ Benign, Score $\geq 6-$ Malignant

\section{RESULTS}

This study included 54 patients. 25 cases were malignant and 29 cases were benign confirmed by histopathology. Alcazar scoring system identified 22 out of 25 malignant tumors and 27 out of 29 benign tumors. The sensitivity and specificity of the scoring system for diagnosing malignancy are $88 \%$ and $93.1 \%$ respectively. The positive predictive value and negative predictive value are $91 \%$ and $90 \%$ respectively (Table 2 to 4 ).

Table 2: Shows histological confirmation.

\begin{tabular}{|ll|}
\hline Benign & Malignant \\
\hline 29 & 25 \\
\hline
\end{tabular}

Table 3: Shows comparison b/w Alcazar scoring and histopathology.

\begin{tabular}{|lll|l|}
\hline & HIPE (M) & HIPE (B) & Total \\
\hline Alcazar $(>6)$ & 22 & 2 & 24 \\
\hline Alcazar $(<6)$ & 3 & 27 & 30 \\
\hline Total & 25 & 29 & 54 \\
\hline
\end{tabular}

Table 4: Shows efficacy of the Alcazar scoring system in diagnosing malignancy.

\begin{tabular}{|ll|}
\hline Statistical parameter & Percentage \\
\hline Sensitivity & 88 \\
\hline Specificity & 93.1 \\
\hline PPV & 91 \\
\hline NPV & 90 \\
\hline
\end{tabular}

The range of age group was 15 to 70 , benign tumor was more prevalent in the age group less than $40 \mathrm{yrs}$. Malignant in age group more than 40yrs. 18 were in menopausal group. Out of which 12 had malignant changes. (Table 5 and Figure 1 to 4 ).

Table 5: Shows univariate analysis of the variables used in evaluation of the adnexal mass.

\begin{tabular}{|lll|}
\hline Variables & $\begin{array}{l}\text { Malignancy } \\
\text { criterion }\end{array}$ & P value \\
\hline $\begin{array}{l}\text { Menopausal } \\
\text { status }\end{array}$ & Postmenopausal & $\mathrm{P}<0.05$ \\
\hline $\begin{array}{l}\text { Thick } \\
\text { papillary } \\
\text { projection }\end{array}$ & Present & $\mathrm{P}<0.001$ \\
\hline Solid areas & Present & $\mathrm{P}<0.001$ \\
\hline Central flow & Present & $\mathrm{P}<0.000$ \\
\hline $\begin{array}{l}\text { Velocimetry } \\
\text { (low } \\
\text { resistance) }\end{array}$ & Present & $\mathrm{P}<0.001$ \\
\hline
\end{tabular}

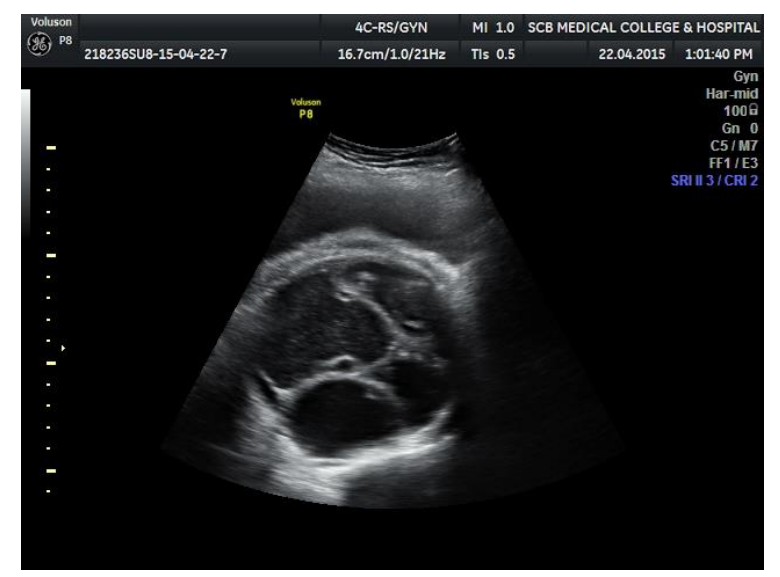

Figure 1: Showing right ovarian cyst with multiple thick septation. 


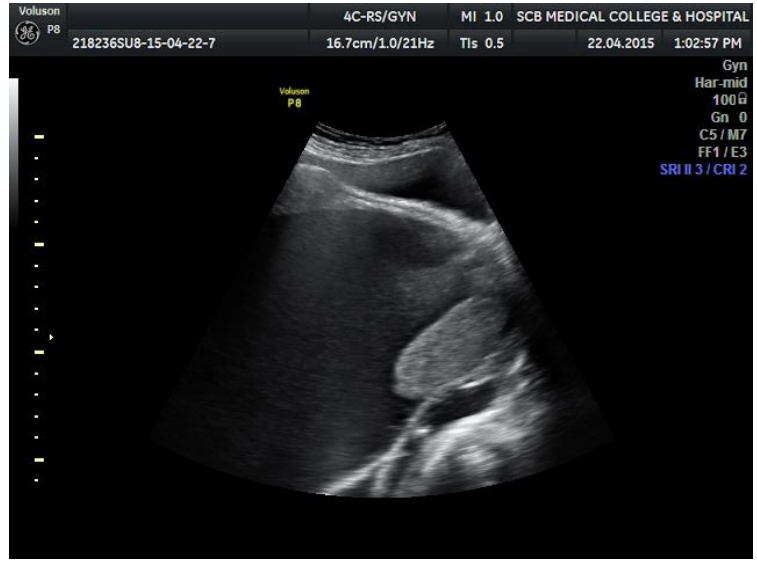

Figure 2: Showing solid areas.

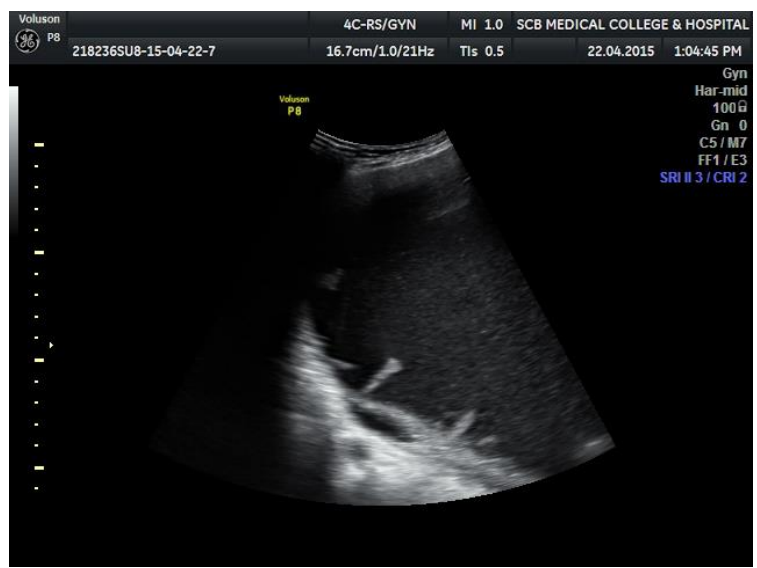

Figure 3: Showing papillary projections.

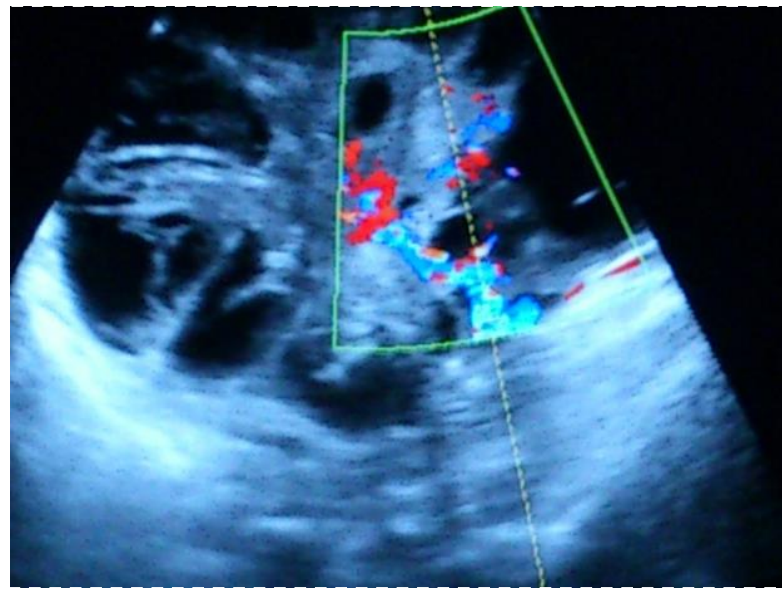

Figure 4: Showing vascularity of the tumor by Doppler.

\section{DISCUSSION}

Objective of the current study was to evaluate the role of ultrasonography, color Doppler and the new Alcazar scoring system in differentiating benign from malignant ovarian tumors.

In our study solid areas were statistically significant $(\mathrm{P}=$ 0.001) in differentiating benign from malignant ovarian tumors. Similar findings were documented by Alcazar $(\mathrm{P}=0.0001),{ }^{1}$ Singh and coworkers $(\mathrm{P}=0.028),{ }^{2}$ Brown et al $(\mathrm{P}=0.001){ }^{8}$

Current study showed thick papillary projections $(>3 \mathrm{~mm})$ to be statistically significant $(\mathrm{P}<0.001)$ in differentiating benign from malignant ovarian tumors. Similarly study by Singh et al showed thick papillary projections $(>3 \mathrm{~mm})$ to be statistically significant $(\mathrm{P}<0.02)^{2}$ Alcazar et al also found thick papillary projections to be statistically significant $(\mathrm{P}<0.0001){ }^{1}$

Color Doppler, Central flow was found to be statistically significant in the present study $(\mathrm{P}<0.000)$. Singh et al showed similar findings $(\mathrm{P}<0.001)^{2}$. Alcazar et al found central flow as predictor of malignancy $(\mathrm{P}<0.0001){ }^{1}$ Brown et $\mathrm{al}^{8}$ found central flow has stronger association with malignancy than the peripheral flow which was more than no flow.

Velocimetry in our study (high velocity/low resistance) was statistically significant $(\mathrm{P}<0.000)$ Similar finding seen in studies by Singh and coworkers $(\mathrm{P}<0.001),{ }^{2}$ Alcazar and colleagues $(\mathrm{P}<0.001),{ }^{1}$ Timor-Trisch colleagues used $\mathrm{RI}<0.46$ as cut-off for detection of malignancy. ${ }^{3}$

Current study showed statistical significance $(\mathrm{P}<0.05)$ when comparing menopausal status of the benign and malignant groups, However, in the series by Alcazar and colleagues, the performance of the scoring system did not alter with menopausal status of the patient, ${ }^{1}$ Singh and coworkers showed menopausal status as an important predictor of malignancy $(\mathrm{P}<0.023) .^{2}$

Current study identified 2 false positive cases -1 mucinous cyst adenoma (solid areas, thick papillary, low resistance) 1 fibroma (solid areas, thick papillary, low resistance) Positive predictive value was $91 \%$. Alcazar et al. had 3 false positive cases (2 cystadenofibroma, 1brenner), ${ }^{1}$ Sassone et al. - 7 cases, ${ }^{4}$ De Priest and colleagues -10 cases $^{5}$, Ferrazi et al. -9 cases. $^{6}$

Current study had 5 false negative cases (endometriod CA, yolk sac tumor, malignant dermoid, serous cyst adenocarcinoma, mucinous cyst adenocarcinoma). Negative predictive value was $90 \%$ Alcazar et al. ${ }^{1}$ and De Priest et al. showed no false negative results. ${ }^{5}$ Sassone et al. had 11 cases, ${ }^{4}$ Ferrazi et al. had 7 cases. ${ }^{6}$

Alcazar scoring system with $100 \%$ sensitivity and $94.9 \%$ specificity is considered better than other 4 scoring systems. ${ }^{1,9}$ This improvement in the diagnostic performance was because (1) the analytical approach was more statistically accurate, (2) only parameters truly predictors of malignancy were included. Alcazar scoring system gave better results due to addition of color Doppler. ${ }^{1,9}$ Central flow and low resistance were more consistently associated with malignancy. ${ }^{1,8}$ Doppler increased the sensitivity and specificity. ${ }^{5}$ 


\section{CONCLUSION}

Alcazar scoring system being simple and easy to memorize is more sensitive and specific in differentiating benign from malignant ovarian masses. However it is highly operator dependent which leads to inter observer variability and needs expert sonologist. ${ }^{1,9}$

\section{ACKNOWLEDGEMENTS}

No assistance was seeked by any companies or authorities. Contribution is mainly from the authors with the support of Dept of Obstetrics and Gynecology.

\section{Funding: No funding sources}

Conflict of interest: None declared

Ethical approval: The study was approved by the Institutional Ethics Committee

\section{REFERENCES}

1. Alcazar JL, Mercee LT, Laparte C, Juardo M, Garcia L. A new scoring system to differentiate benign from malignant adnexal mass. Am J Obs Gyn. 2003; 188:685-92.

2. Singh U, Kohli N, Nisha, Ekta. Evaluation of a new scoring system to differentiate between benign and malignant adnexal mass. The Journal of Obstetrics and Gynaecology of India. 2006;56(2):162-5.

3. Timor - Tritsch IE, Lerner JP, Monteagudo A, Santos R. Transvaginal ultrasonographic characterization of ovarian masses by means of colour flow directed Doppler measurements and a morphological scoring system. Am J Obs Gyn. 1993;168:909-13.

4. Sassone AM, Timor-Tritsch IE, Artner A, Westhoff C, Warren WB. Transvaginal sonographic characterization of ovarian disease: Evaluation of a new scoring system to predict ovarian malignancy. Obstet Gynecol. 1991;78:70-6.

5. DePriest PD, Shenson D, Fried A, Hunter JE, Andrews SJ, Gallion HH, et al. Amorphology index based on sonographic findings in ovarian cancer. Gynecol Oncol. 1993;51:7-11.

6. Ferrazzi E, Zanetta G, Dordoni D, et al. Transvaginal ultrasonographic characterization of ovarian masses: A comparison of five scoring systems in a multicenter trial. Ultrasound Obstet Gynecol. 1997;10:192.

7. Ameye L, Valentine L, Testa AC, Van Holsbeke C, Domali E, Van Huffel S, et al. A scoring system to differentiate malignant from benign masses in specific ultrasound-based subgroups of adnexal tumors. 2009;33(1):92-101.

8. Brown DL, Doubilet PM, Miller FH, et al. Benign and malignant ovarian masses: selection of the most discriminating gray-scale and Doppler sonographic features. Radiology. 1998;208:103-10.

9. Dhwani Desai, Desai VA, Verma RN, Shrivastava J. Role of gray scale and color Doppler in differentiating benign from malignant ovarian masses. Midlife Health. 2010;1(1):23-5.

10. Ananya Sinha, Chella Hariharan, Rahul K Chaudhary: preoperative evaluation of ovarian tumors in the rural population-clinical features, grey scale ultrasound, colour doppler, serum ca-125 and alcazar score in predicting malignancy: journal of evolution of medical and dental sciences www.jemds.com/latest-articles.php?at_id=996.

Cite this article as: Sahu M, Nathasha HK. Evaluation of the alcazar scoring system in differentiating benign from malignant ovarian tumors. Int J Reprod Contracept Obstet Gynecol 2015;4:1004-7. 